\title{
Thermo-mechanical response of UHPFRC at early age - Experimental study and numerical simulation
}

\author{
Aicha Kamen*, Emmanuel Denarié, Hamid Sadouki, Eugen Brühwiler \\ Laboratory of Maintenance and Safety of Structures (MCS), Ecole Polytechnique Fédérale de Lausanne (EPFL), Station 18, CH-1015 Lausanne, Switzerland
}

Received 12 July 2007; accepted 22 January 2008

\begin{abstract}
The thermal effects on the Ultra High Performance Fiber Reinforced Concrete (UHPFRC) behavior are still not completely known. Under high temperatures, the processes that interact at early age are thermo-activated. All the experimental results obtained within this research confirmed it. Besides, certain authors observed a non-monotonous effect of temperature on the autogenous shrinkage and the creep of normal and high performance concretes. To clarify the thermal effect on the early age UHPFRC behavior an extensive experimental study was carried out. Tests results showed a non-monotonous effect of temperature on the autogenous shrinkage. In addition, finite element numerical simulations were performed to predict the experimental results and to validate existing models for different curing conditions. These models are necessary to predict accurately the deformations, the stresses and the damage (cracking) in the case of structural elements subjected to in-situ temperature variations. (C) 2008 Elsevier Ltd. All rights reserved.
\end{abstract}

Keywords: High performance concrete; Temperature effect; Shrinkage; Early age

\section{Introduction}

Cementitious materials with low water/binder ratios are sensitive to early age cracking. Previous research has shown that cracks can develop when the cementitious material is internally or externally restrained to shrink freely [1-3]. However many factors interact during early age and can influence the occurrence of cracks, see Fig. 1a. According to our review of literature, little attention has been given to study thermal effects on UHPFRC early age behavior, while in the last decades substantial attention has been given to the evaluation and modeling of the thermal effect on early age behavior for other cementitious materials (cement paste, conventional concrete and high performance concrete) $[1,2,4]$. Previous works on heat treated UHPFRC showed that treatment at high temperatures after the setting: 1) enhances the microstructure and the compressive strength of the material [5-8], 2)

\footnotetext{
* Corresponding author.

E-mail addresses: aicha.kamen@epfl.ch (A. Kamen), emmanuel.denarie@epfl.ch (E. Denarié), hamid.sadouki@epfl.ch (H. Sadouki), eugen.bruehwiler@epfl.ch (E. Brühwiler).
}

eliminates shrinkage and 3) reduces creep [5]. Besides, the heat treatment results in high proportion of bounded water, accelerates the pozzolanic reaction and modifies the hydrates structures $[7,9]$.

Variations of curing conditions can be considered as most influential early age factor in a given structure. A better understanding of its influence may be beneficial in mitigating high early age stresses under restrained conditions and hence reducing the cracking risk. To investigate this influence, an intensive experimental study was conducted using a Temperature Stress Testing Machine (TSTM) at MCS [10] on the basis of previous works $[1,2,11,12]$. The focus of this research was to investigate the UHPFRC early age autogenous shrinkage and shrinkage induced stresses at quasi-isothermal and realistic temperature conditions.

In addition, to model our experimental results, numerical simulations were made with finite element software MLS (Multi Layer System) [13], which considers several phenomena, Fig. 1a, and their interactions through thermal, hygral, maturity and mechanical models. The detail of the models can be found in Refs. [13-15]. Besides, the aim of these numerical simulations is to validate the models implemented in this software under 


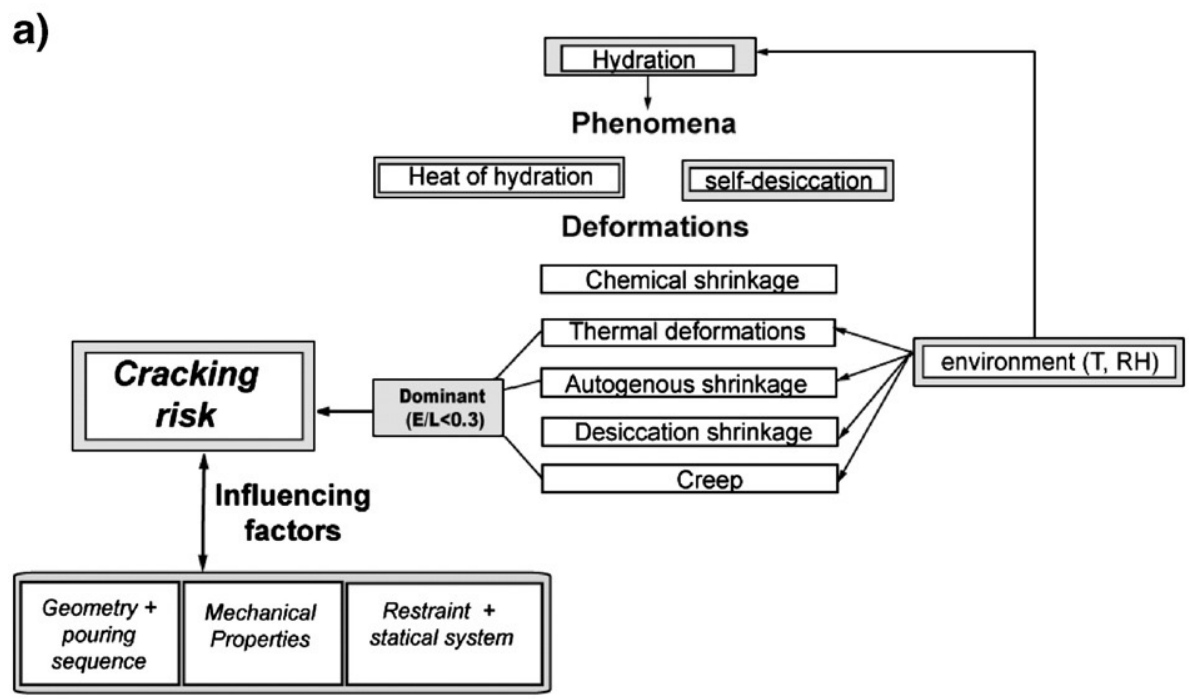

b)

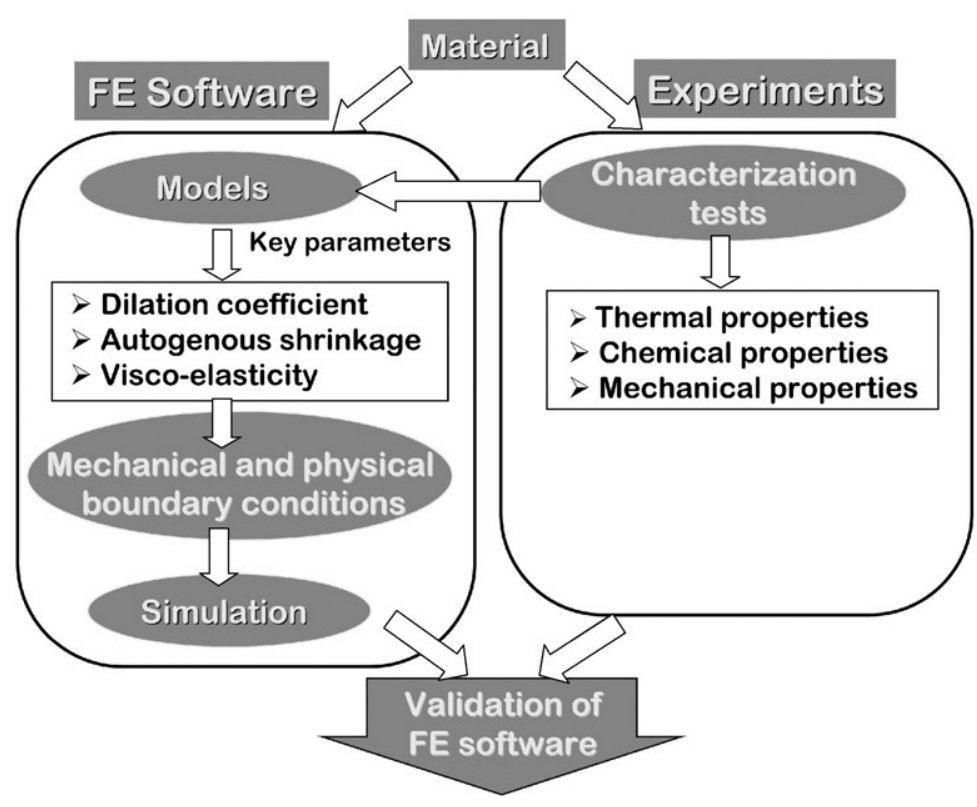

Fig. 1. Cementitious materials behavior a) and numerical simulation steps b).

various curing conditions, Fig. $1 \mathrm{~b}$. These models are necessary to predict accurately the deformations, the stresses and the damage (cracking) in the case of structural elements subjected to in-situ temperature variations.

\section{Material}

UHPFRC of the CEMTEC multiscale $^{\circledR}$ family [16] is produced by adding steel fibers to ultra-compact cementitious matrix. The specific Ultra-High Performance Fiber Reinforced Concrete used in this study is characterized by an extremely low permeability, a high strength and a tensile strain hardening behavior [17-19]. The tested CEMTEC ${ }_{\text {multiscale }}{ }^{\circledR}$ mix proportions are given in Table 1 . Despite its very low water/binder ratio (0.131), it exhibits excellent rheological properties in the fresh state; thanks to its high binder content.

\section{Experiments}

\subsection{Testing procedure}

The tests were performed on insulated dog-bone shaped specimens using a Temperature Stress Testing Machine (TSTM). The first device (FS), Fig. 2a, helps to determine the free deformation, and the second one (RS), Fig. $2 b$, the

Table 1

UHPFRC recipe

\begin{tabular}{ll}
\hline Material & {$\left[\mathrm{kg} / \mathrm{m}^{3}\right]$} \\
\hline Cement/silica fume/fine sand & $1410.2 / 367.0 / 80.4$ \\
Water/superplasticizer & $200.1 / 46.5$ \\
$\begin{array}{l}\text { Steel fibers (straight macro fibers: } l_{\mathrm{f}}=10 \mathrm{~mm}, \varnothing_{\mathrm{f}}=0.2 \mathrm{~mm} \\
\quad \text { and micro fibers: steel wool) }\end{array}$ \\
\hline
\end{tabular}


a)

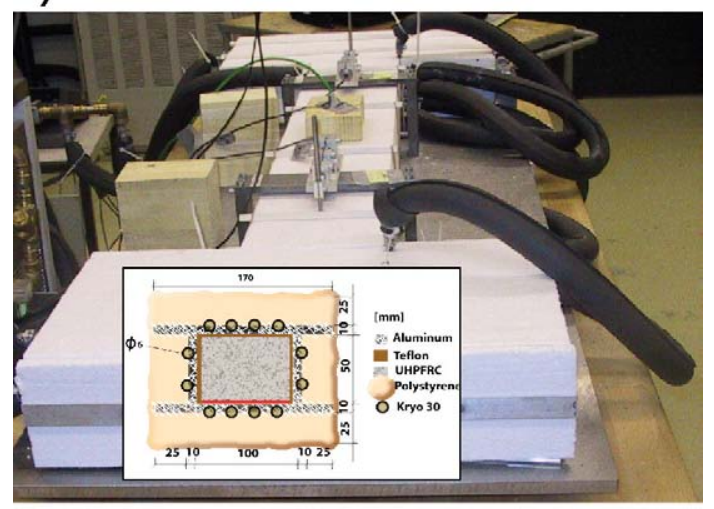

b)

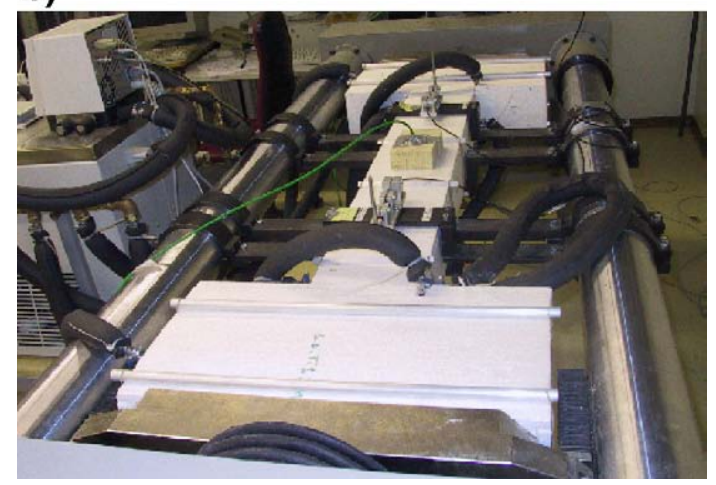

Fig. 2. Set up of the TSTM: free shrinkage a) and restrained shrinkage b).

evolution of internal stresses generated under restrained conditions. Shortly after filling of the moulds, the specimens start to deform. Following the procedure developed by [2], at the end of the setting time, the specimen is brought back to its initial position in the restrained shrinkage set-up. This operation induces stresses within a short period of time, which are measured by the load cell. When the initial position of deformation is attained, the control mode is switched to force control and a creep sequence is started, which lasts until a threshold level of deformation is reached [20]. In parallel, the temperature inside each UHPFRC specimen is recorded simultaneously. In the aim to investigate the thermal effect on early age UHPFRC behavior, different curing conditions were applied $\left(20^{\circ} \mathrm{C}, 30^{\circ} \mathrm{C}\right.$ and variable temperature evolution from 20-32-20). Each test was carried out for 1 week.

\subsection{Autogenous shrinkage and induced stresses under $20{ }^{\circ} \mathrm{C}$ quasi-isotherm temperature}

Fig. 3a shows the results obtained in the FS set-up for 2 specimens tested in similar conditions. Examination of this figure reveals five steps. The first one, up to (1), corresponds to the chemical shrinkage (Le Châtelier contraction) that starts after the first water-cement contact. The second step (2) is characterized by swelling, also observed by [18] on a closely related material (with $\mathrm{W} / \mathrm{C}=0.18$ ) and by [21] on high performance concrete (with $\mathrm{W} / \mathrm{C}=0.33$ ). This swelling cannot be attributed to thermal dilation because the temperature starts to increase later (see the temperature evolution, Fig. 3a) but may be attributed to the crystallization of the hydration products [22]. The third step (3) corresponds again to the chemical shrinkage. During the forth step (4), one notes a quasi-stop of the development of shrinkage for a limited period, from 43 to $48 \mathrm{~h}$ superimposed with a slight swelling due to the small temperature difference of $1{ }^{\circ} \mathrm{C}$ as shown in Fig. 3a. The local deceleration of the development of shrinkage in this period, also observed and discussed by [18], is not yet fully understood. The last stage (5) after $48 \mathrm{~h}$ is the main part of the autogenous shrinkage resulting from self-desiccation [23].

The measured autogenous shrinkage varies between 105 and $140 \mu \mathrm{m} / \mathrm{m}$ at 7 days. The autogenous shrinkage of the tested UHPFRC is two times lower at same age than that measured on cement paste with $\mathrm{W} / \mathrm{C}=0.4$ and containing $5 \%$ of silica fume [24] and that measured on high performance concrete with W/ $\mathrm{B}=0.25$ and containing $10 \%$ of silica fume [4]. This moderate autogenous shrinkage is attributed to the low degree of hydration (about $30 \%$ after 90 days). In fact, autogenous shrinkage results and develops during the hydration progress under sealed conditions, and its evolution is strongly related to the hydration degree at early age as shown and reported in $[2,10]$.

The stresses generated by the autogenous and thermal dilation in the RS set-up for 2 specimens tested in similar conditions are shown in Fig. 3b. The stresses increase over time

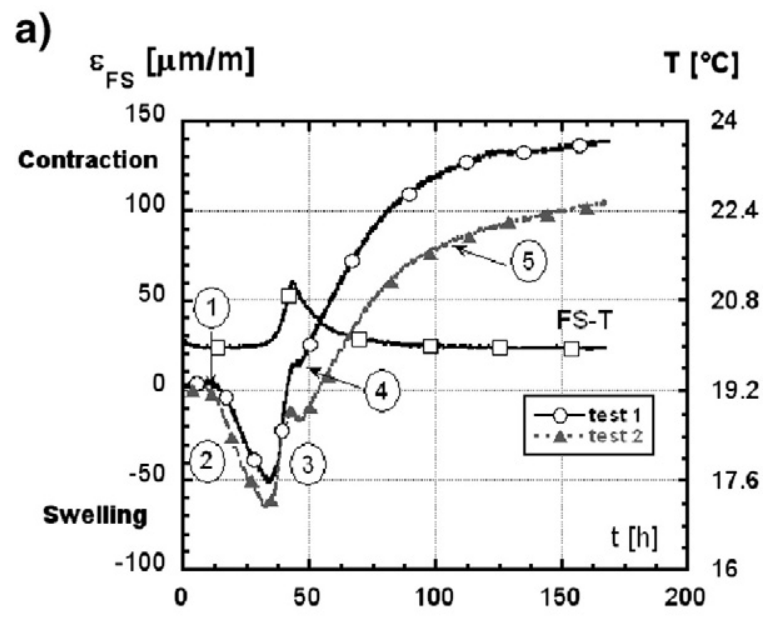

b)

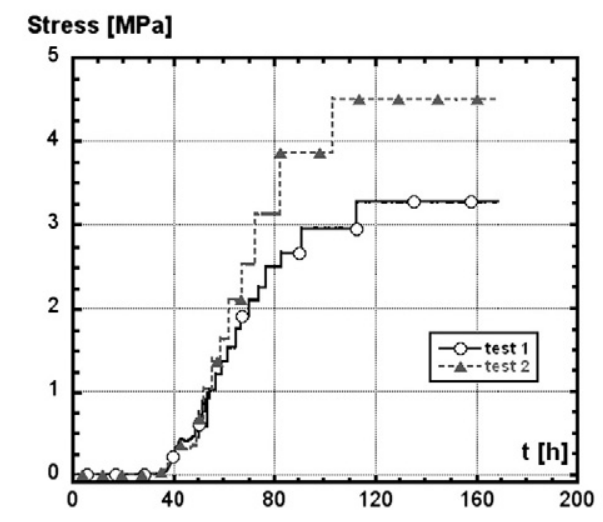

Fig. 3. Curing $20{ }^{\circ} \mathrm{C}$ : evolution of free shrinkage a) and stresses under incremental full restraint $b$ ). 
with the increase of the modulus. This stresses increase is however largely mitigated by the visco-elastic response of the UHPFRC at early age [25]. The induced stress reached 30 to $47 \%$ of the tensile strength $\left(f_{\mathrm{t}} *\right)$ obtained at the end of each test. However, the UHPFRC is less sensitive to cracking risk at early age (first 7 days). This is confirmed by visual analysis of other specimens, at the end of incremental tests where no cracks were detected. Note that the induced stresses keep on increasing with age because the autogenous shrinkage continues to develop after the first week. As the elastic modulus develops faster than the tensile strength [26], hence higher stresses susceptible to induce cracking can develop at long-term. Finally, note that the occurrence of cracks in conventional concrete is likely when the stress to strength ratio reaches a value between 0.4 and 0.5 [27]. This is not the case for the present UHPFRC which is characterized by a high tensile strength and a high capacity of deformation $(0.2 \%$ in the hardening domain). Consequently its early age cracking sensitivity at such stress levels is reduced.

\subsection{Autogenous shrinkage and induced stresses under $30{ }^{\circ} \mathrm{C}$ quasi-isotherm temperature}

Fig. 4a shows the results obtained in the FS set-up for $20^{\circ} \mathrm{C}$ and $30{ }^{\circ} \mathrm{C}$. This figure shows the same five steps as observed for $20^{\circ} \mathrm{C}$ and a backward shift of the curve for $30^{\circ} \mathrm{C}$ which is related to the thermo-activation of the hydration process. Consequently, hydration products and self-desiccation at early age develop earlier and faster, as shown by the experimental results [23]. This leads to an increase of autogenous shrinkage with respect to that for $20^{\circ} \mathrm{C}$. The temperature influences both the kinetics and the amplitude of autogenous shrinkage, because of its influence on the microstructure development [7]. Indeed the formed hydrates confine the porous structure and thus reduce the pore size, consequently leading to higher capillary tensions and more important contraction of the solid for $30{ }^{\circ} \mathrm{C}$. This result is coherent with [4] for high performance concrete. The maximal swelling is equal to that measured for $20{ }^{\circ} \mathrm{C}(67 \mu \mathrm{m} / \mathrm{m}$ after $20 \mathrm{~h}$ ). The measured autogenous shrinkage reaches $202 \mu \mathrm{m} / \mathrm{m}$ after $168 \mathrm{~h}$, and is increased by $44 \%$ with regard to the highest autogenous shrinkage measured for $20^{\circ} \mathrm{C}$ (test 1 ).

The comparison of stress evolution for 20 and $30{ }^{\circ} \mathrm{C}$ is represented in Fig. 4b. This figure shows that the induced stresses develop earlier and faster for $30{ }^{\circ} \mathrm{C}$, due to the fast development of the driving forces "hydration, self-desiccation and consequently autogenous shrinkage". After 7 days, the stresses are slightly higher compared to $20^{\circ} \mathrm{C}$ and consequently likelihood of UHPFRC cracking is higher. Indeed $\left(\sigma / f_{\mathrm{t}} *\right)$ ratio for $30{ }^{\circ} \mathrm{C}$ increased compared with that obtained for $20{ }^{\circ} \mathrm{C}$, as shown in Fig. 4b. This may be attributed to internal damage due to the occurrence of premature micro-cracks for $30{ }^{\circ} \mathrm{C}$.

\subsection{Autogenous shrinkage under $10{ }^{\circ} \mathrm{C}$ quasi-isotherm temperature}

Fig. 5a shows the results obtained in the FS set-up for $10^{\circ} \mathrm{C}$ and $20{ }^{\circ} \mathrm{C}$. According to this figure, we can observe the same steps for 10 and $20^{\circ} \mathrm{C}$. However, the autogenous shrinkage

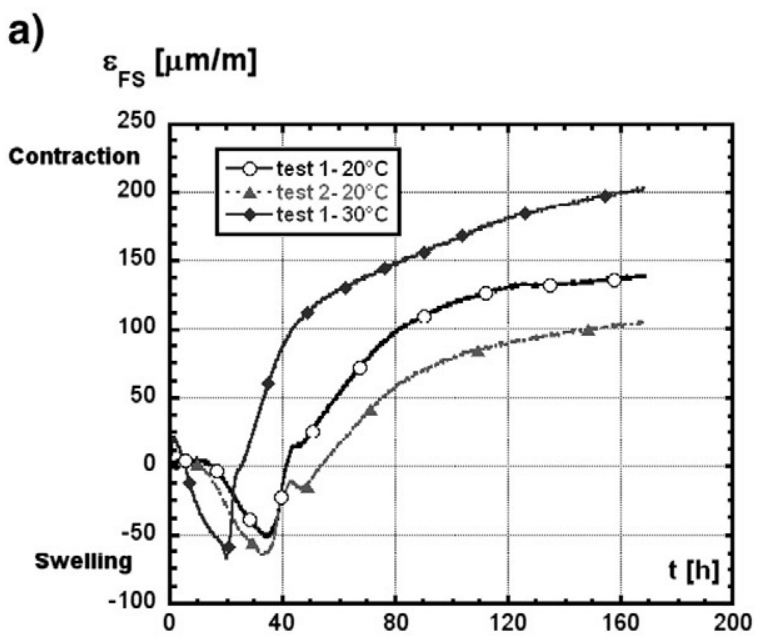

b)

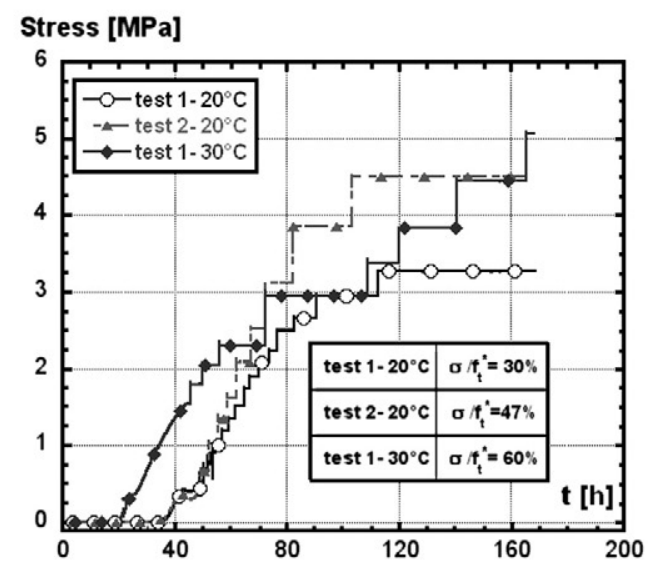

Fig. 4. Test results comparison for 20 and $30{ }^{\circ} \mathrm{C}$ : evolution of free shrinkage a) and stresses under incremental full restraint $b$ ).

kinetics, after the setting time are different. The rate of deformation increased significantly until the end of the measurements, reflecting the reverse effect of temperature on the autogenous shrinkage. To clarify this tendency, the curves were zeroed at the end of swelling, Fig. 5b. Our results are in agreement with results found in the literature $[1,2,28]$. [1] studied the influence of temperature $\left(5,13,20\right.$ and $\left.45^{\circ} \mathrm{C}\right)$ on a concrete with $\mathrm{W} / \mathrm{C}=0.4$ and [2] studied the influence of temperature $\left(10,20\right.$ and $\left.30^{\circ} \mathrm{C}\right)$ on concretes with various $\mathrm{W} / \mathrm{C}$ ratios $(0.30,0.35$ and 0.45$)$. Finally, all these results show that as well the increase and the decrease of temperatures increased the autogenous shrinkage at early age with regard to $20^{\circ} \mathrm{C}$. This tendency is reversed at long-term; [1] observed that the autogenous shrinkage under low temperatures becomes lower than that measured at $20^{\circ} \mathrm{C}$ from 12 days until the end of the measurement after 33 days.

[2] attributed this contradictory effect to the complex combination of three parameters. The importance of each parameter varies with the type of the material and the curing conditions:

- The shrinkage caused by the capillary depression mechanism may be reduced by the higher strength of the solid skeleton, which is higher under high temperatures at early age. 
a) $\varepsilon_{\mathrm{FS}}[\mu \mathrm{m} / \mathrm{m}]$

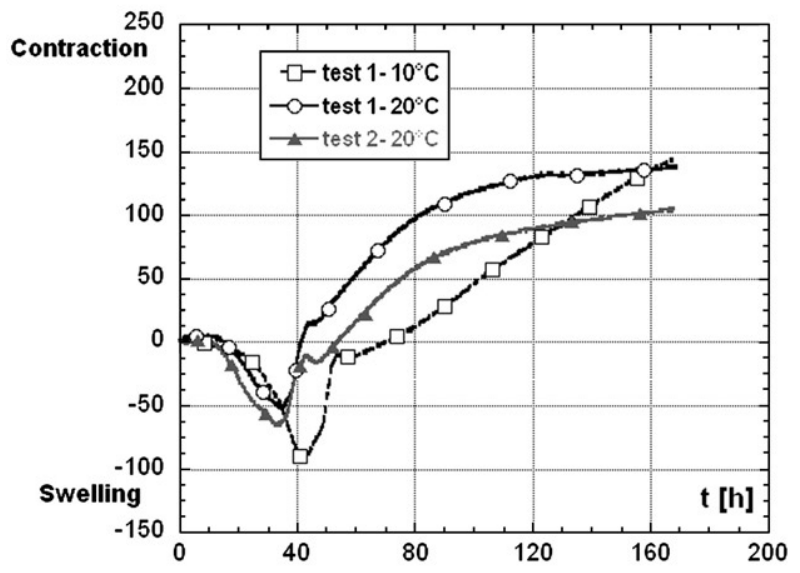

b) $\varepsilon_{\mathrm{FS}}[\mu \mathrm{m} / \mathrm{m}]$

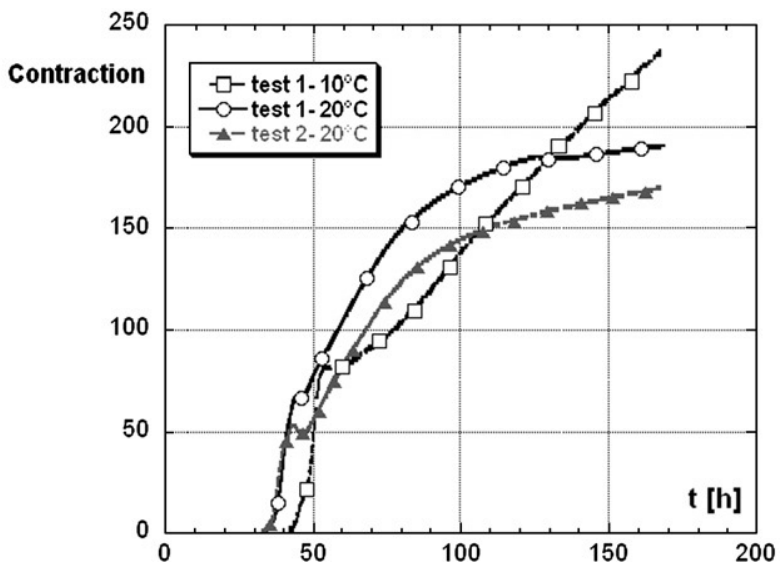

Fig. 5. Test results comparison for 10 and $20^{\circ} \mathrm{C}$ : evolution of free shrinkage as measured a) and evolution of free shrinkage zeroed at the end of swelling phase b).

- The second effect can be related to the pores distribution. [29] as well as [30,31] observed the higher thermal curing conduct to a more heterogeneous microstructure and a more unrefined porous structure. As the capillary depressions, depend on the pores size, this means that the shrinkage should be reduced for high temperatures.

- The third parameter at the origin of the reduction of the free shrinkage under high temperatures is the reduction of the tension in the interface gas-liquid in the capillary pores. According to [32], the tension in the interface gas-liquid is dependent on the temperature. For pure water, the tension is weaker by $10 \%$ at $60{ }^{\circ} \mathrm{C}$ with regard to $20^{\circ} \mathrm{C}$.

In conclusion, the more significant free shrinkage for $10{ }^{\circ} \mathrm{C}$ is related to the capillary depressions in the material characterized by low development of strength at early age. The intensity of the capillary tension depends strongly on the modification of the tensions in the gas-liquid interface in pores and of the pores distribution.

\subsection{Autogenous shrinkage and induced stress under realistic temperature}

One notes that the realistic conditions were considered as a special case to take into account the deformation due to the heat release during binder hydration.

The real evolution of temperature in the core of the UHPFRC layer of composite beams (UHPFRC-NC) investigated by [18], was applied to study the early age behavior of the current UHPFRC under realistic temperatures. An equivalent temperature history was imposed by means of the control bath software (Wintherm), Fig. 6a. The temperature evolution recorded within the FS and RS specimens are represented in Fig. 6b. The measured temperature within the two specimens follows perfectly the imposed temperature.

Fig. 7a shows the evolution of free deformation. Three different stages can be observed. The first stage corresponds to a low initial chemical shrinkage that starts to develop from the first contact water/cement. The second stage refers to the

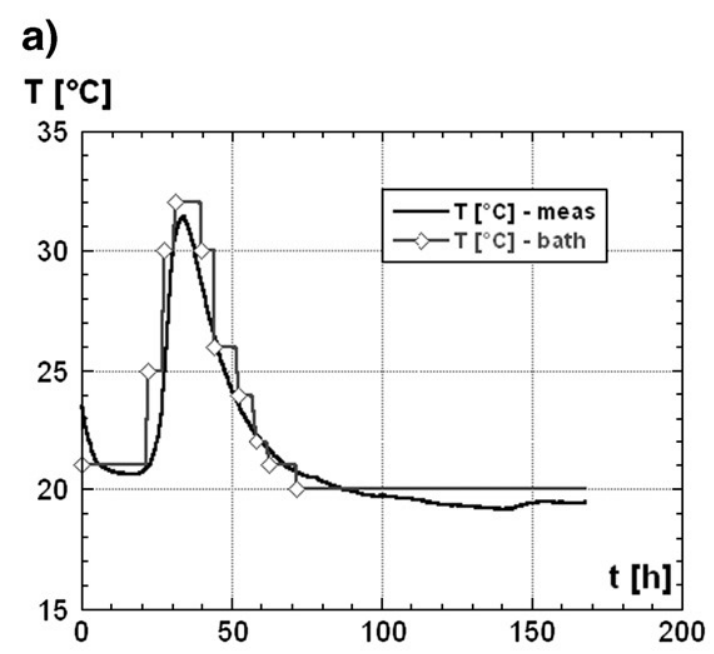

b)

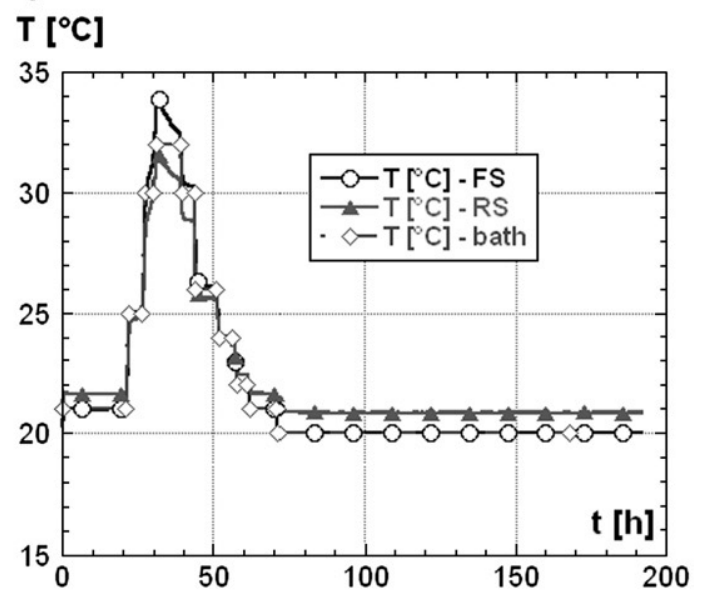

Fig. 6. Measured temperature in the core of UHPFRC layer in composite bean [12] and the equivalent curve imposed as realistic curing a) and measured temperature in the core of FS and RS specimens b). 
a)

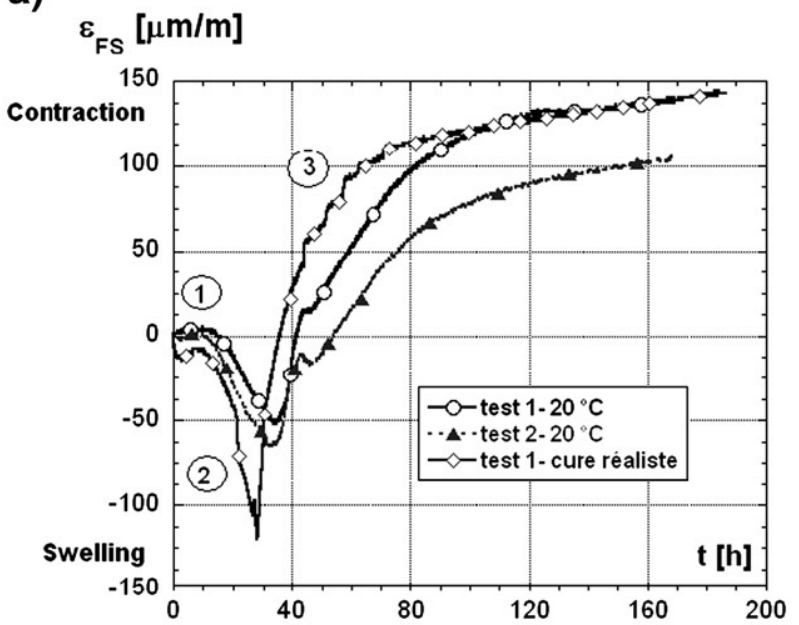

b)

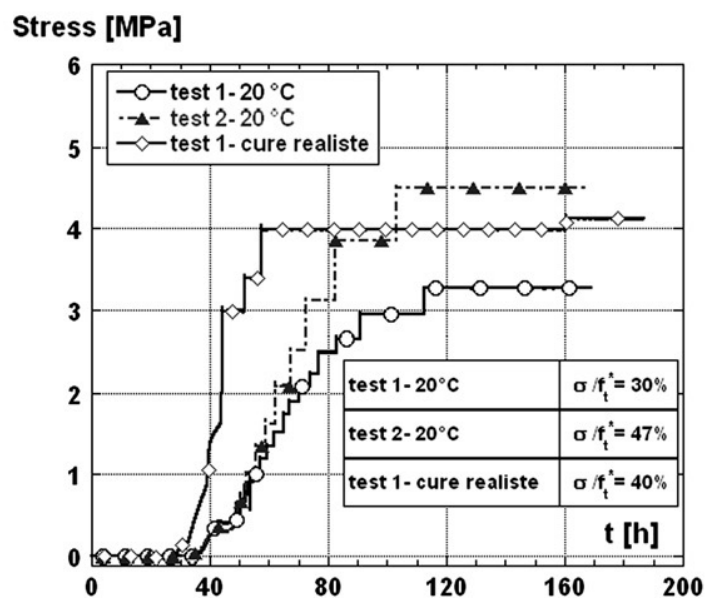

Fig. 7. Test results comparison for $20^{\circ} \mathrm{C}$ and realistic temperature: evolution of free shrinkage a) and stresses under incremental full restraint b).

swelling related to the temperature increase during the hydration process, and the third stage is characterized by the shrinkage during the decreasing phase of temperature. Comparison of free deformation under quasi-isothermal and realistic temperature shows an increase of the swelling deformation at the early age due to the additional thermal dilation which adds to the swelling caused by the crystallization of the hydration products observed also under quasi-isothermal temperature. However, the free deformation reached after 7 days, for the realistic cure is similar to that measured for $20^{\circ} \mathrm{C}$, as shown in Fig. 7 a.

The stresses evolution under realistic and quasi-isothermal temperature of $20{ }^{\circ} \mathrm{C}$ is represented in Fig. 7b. This figure shows at early age, a faster development of stresses under realistic curing, due to a thermo-activation of the hydration process during the temperature evolution, leading to a faster self-desiccation and autogenous shrinkage development. In addition, the fast hydration results in a densification of the UHPFRC microstructure and an increase of its stiffness, which makes difficult the application of successive stress increments to bring back the specimen to its initial length after the imposed deformation threshold has been reached.
4. Numerical simulations of autogenous shrinkage and induced stresses for different curing conditions

\subsection{Autogenous shrinkage prediction for different quasi- isotherm temperature}

The input data for these numerical simulations are obtained from experimental results namely: the thermal properties deduced by applying the Danish model $[10,14,18]$ to semiadiabatic test results [10], the compressive strength, tensile strength, elastic modulus and the autogenous shrinkage. The dimensions and the boundary conditions considered for these simulations are shown in Fig. 8.

A series of numerical simulations was performed to validate the maturity concept implemented in MLS for different curing conditions based on the autogenous shrinkage measured at $20{ }^{\circ} \mathrm{C}$ (as input). Thus for the following simulations, the change consists only on the boundary conditions according to each case i.e. $\left(30^{\circ} \mathrm{C}\right.$, $10{ }^{\circ} \mathrm{C}$ and realistic temperature). Fig. 9 shows the prediction obtained for $30^{\circ} \mathrm{C}$ until 7 days. We can observe that the maturity concept applies for $30^{\circ} \mathrm{C}$, because the model describes very well the evolution of the autogenous shrinkage under this temperature and approaches well the experimental results performed at this temperature both in expansion and contraction phase.

Further numerical simulations were performed to validate the application of the maturity concept for low temperatures and its ability to reproduce the inverse effect of temperature on the autogenous shrinkage as observed at early age. Note that in these simulations a corrective factor of the activation energy for low temperatures is considered. The activation energy as function of temperature proposed by $[33,34]$ is expressed by the following equations:

for $\rightarrow T \geq 20^{\circ} \mathrm{C} \Rightarrow E(T)=33.5 \mathrm{~kJ} / \mathrm{mol}$
for $\rightarrow T<20^{\circ} \mathrm{C} \Rightarrow E(T)=33.5+\Delta Q / R(20-T)[\mathrm{kJ} / \mathrm{mol}]$

According to theses results, we can observe that even the variation of the corrective factor does not allow a better prediction of the UHFRPC free deformation. In parallel, numerical simulations based on HPC results, obtained by [2] were performed to validate our results. The overall results of these simulations showed a similarity with the current UHPFRC results i.e. the applicability of the maturity concept to describe the autogenous shrinkage for 20 and $30{ }^{\circ} \mathrm{C}$, but not for $10^{\circ} \mathrm{C}$ as shown in Fig. 10b [10]. Thus, we can conclude that the current maturity model requires an adaptation to describe correctly the behavior of cementitious materials for low temperatures. [32] also

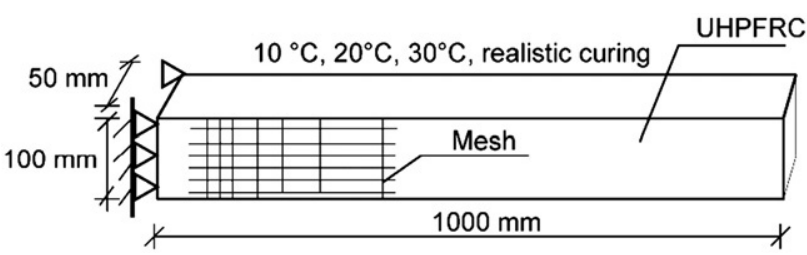

Fig. 8. Dimensions and boundary conditions of UHPFRC specimen for autogenous shrinkage simulations. 
showed that the traditional maturity concept is not valid to describe both autogenous shrinkage and self-desiccation evolutions.

According to [32], the pozzolanic reaction has generally an activation energy different from the cement hydration. For that purpose, the authors used two activation energies (a smaller energy traducing the cement hydration at early age and a higher one in long-term traducing the pozzolanic reaction) to describe the evolution of the internal relative humidity and the deformation of cement paste with $\mathrm{W} / \mathrm{C}=0.3$ and containing $20 \%$ of silica fume. This adaptation gave satisfactory results. In theory, the properties, which result from the combination of various processes with various activation energies, cannot be described by single activation energy [35]. In conclusion, the maturity concept must be adapted to take into account simultaneous reactions with different sensitivities to the temperature.

\subsection{Prediction for realistic temperature}

\subsubsection{Coefficient of expansion (CDT) as given in literature}

Until now, the evolution of thermal dilation coefficient at early age arouses questions and is not completely understood. And in the literature, there are contradictions about the CDT evolutions for cement pastes and normal concretes.

Certain authors found that the CDT decreases from a high value to a constant value [36-38]. Several researches which are in agreement with this finding were enumerated by [37].

Kada et al. [36] studied concretes having different water-tocement ratios $(0.3 ; 0.35$ and 0.45$)$. For concretes having waterto-cement ratios of 0.45 and 0.35 , the authors found that the CDT decrease from $32 \times 10^{-6}$ to $6.5 \times 10^{-6}\left[{ }^{\circ} \mathrm{C}^{-1}\right]$ and remains constant at this value after. For the concrete having water-tocement ratio 0.3 ; the authors found that the CDT varies from $13 \times 10^{-6}$ to $7.6 \times 10^{-6}$. Finally, the authors proposed to consider a value 3 to 4 times that of hardened concrete at the beginning of setting, than the CDT decreased until the end of setting to remain constant thereafter.

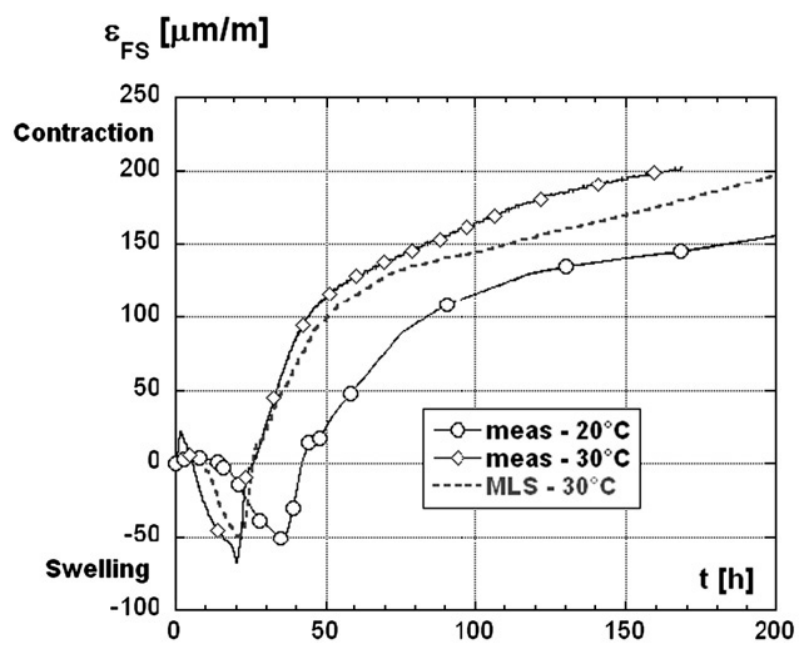

Fig. 9. Autogenous shrinkage measured and predicted results comparison: for 20 and $30^{\circ} \mathrm{C}$. a)

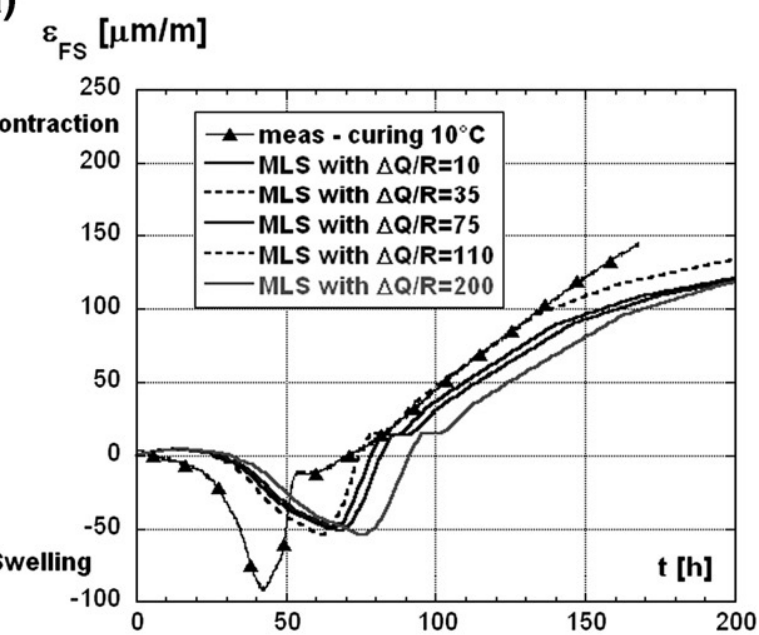

b)

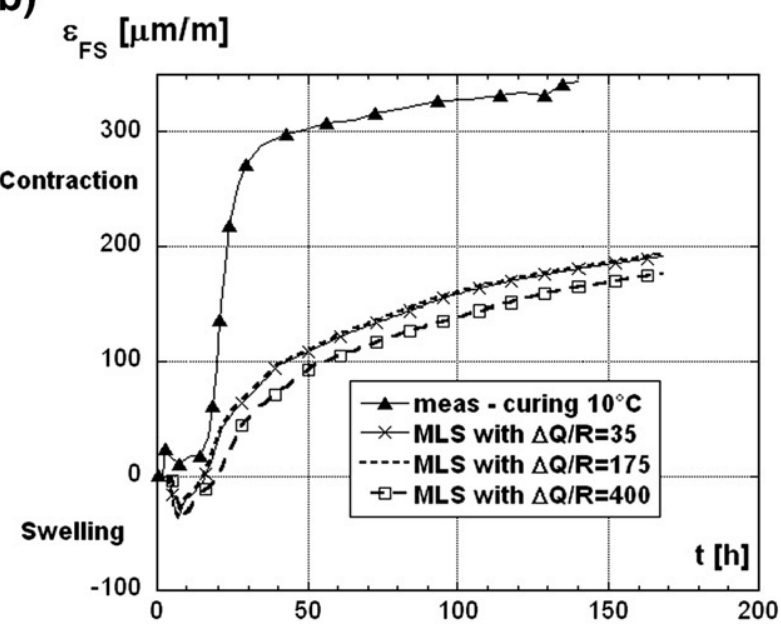

Fig. 10. Free deformation prediction with different $\Delta(Q / R)$ : UHPFRC a) and HPC b).

Recently, [1] found that the concrete with water-to-cement ratio of 0.4 , has high CDT before setting $\left(20 \times 10^{-6}\left[{ }^{\circ} \mathrm{C}^{-1}\right]\right)$. After the formation of solid structure, the $\mathrm{CDT}$ reduces, reaching a minimum value around the final set. After that the CDT increases as self-desiccation proceeds. This result is coherent with results obtained by [39]. The authors studied particularly the influence of internal moisture on the CDT. They found that the CDT, at fully dried and saturated conditions was the same, about $11 \times 10^{-6}\left[{ }^{\circ} \mathrm{C}^{-1}\right]$. The $\mathrm{CDT}$ reached a maximum value at intermediate relative humidity between ( 45 and $60 \% \mathrm{RH})$.

According to what precedes, it becomes difficult to carry a critical judgment on the results obtained by other authors. Nevertheless in all studies, a high value is given at early age and the initial variation of CDT is related to the free water that have a CDT twenty times higher than the others constituents.

Moreover, investigations accounting for the thermal dilation expansion of this specific material are inexistent. However, we have exploited the values of CDT proposed by [18]. The author proposed the CDT evolution showed in Fig. 12a, based on findings of $[36,37]$. 
For instance the first value $40 \times 10^{-6}\left[{ }^{\circ} \mathrm{C}^{-1}\right]$, was fixed similar to that mentioned by [37] who state that the CDT value of concrete is $40 \times 10^{-6}\left[{ }^{\circ} \mathrm{C}^{-1}\right]$ in fresh state, value calculated from the mixing law i.e. from the volumetrically weighted average of the coefficients of the concrete components [36].

Finally, one underlines that a constant value of CDT is often considered in program calculation, while it is known that it varies strongly with concrete mixture and the time $[36,37,40]$.

\subsubsection{Autogenous shrinkage prediction under realistic temperature}

Additional numerical simulations were performed to validate the maturity concept for realistic temperature. Fig. 11 shows the results of this numerical analysis. The first deformation prediction under a realistic temperature using a variable coefficient of expansion (CDT) (see Fig. 11a) as proposed by [18], based on the literature, is completely different with regard to our experimental results. The second validation test was established by adopting a constant value of the CDT of $12 \times 10^{-6}\left[{ }^{\circ} \mathrm{C}^{-1}\right]$ recommended by [41]. With this adaptation, we can observe that the prediction is more representative of the experimental deformation evolution under the realistic condition. In particular, the initial phase (below the first $26 \mathrm{~h}$ ) and the final phase of current UHPFRC results (beyond $70 \mathrm{~h}$ ). This allowed us to conclude that the initial value of the CDT proposed for the UHPFRC by [18] is overestimated.

To overcome this problem and to predict our experimental deformation under the realistic temperature, several profiles of CDT were proposed until obtaining an accurate prediction. A CDT varying between $25 \times 10^{-6}$ and $12.5 \times 10^{-6}\left[{ }^{\circ} \mathrm{C}^{-1}\right]$, as shown in Fig. 12b. This figure showed that the CDT decreases during the temperature increase (heating phase), this finding is coherent with results obtained by other authors, but during the cooling phase the CDT remains constant and does not increase as found by $[39,40]$. This figure showed that this CDT profile reproduces well our experimental results.

One notes that the prediction with this CDT profile approaches the prediction obtained with a constant CDT of

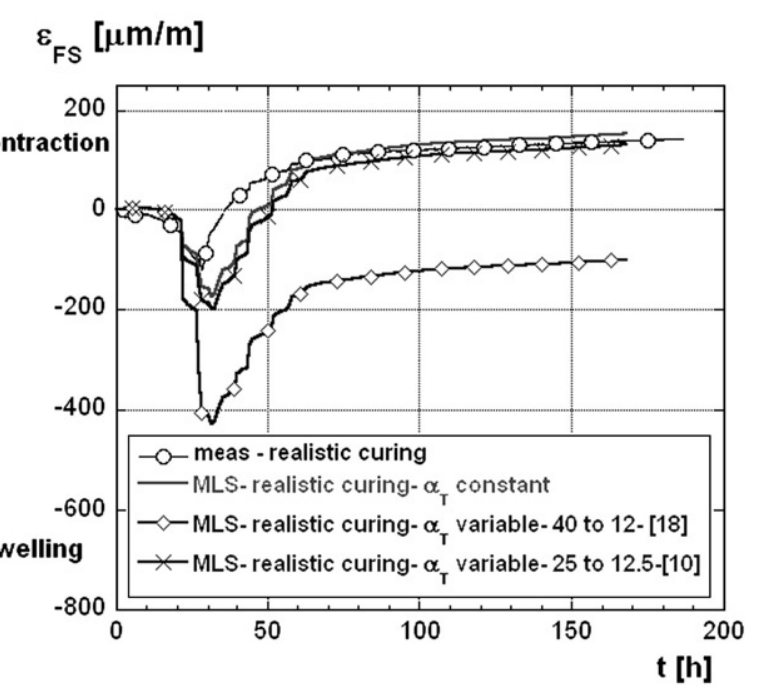

Fig. 11. Autogenous shrinkage test and predicted results comparison: for $10{ }^{\circ} \mathrm{C}$ a) and for realistic temperature evolution b). a)
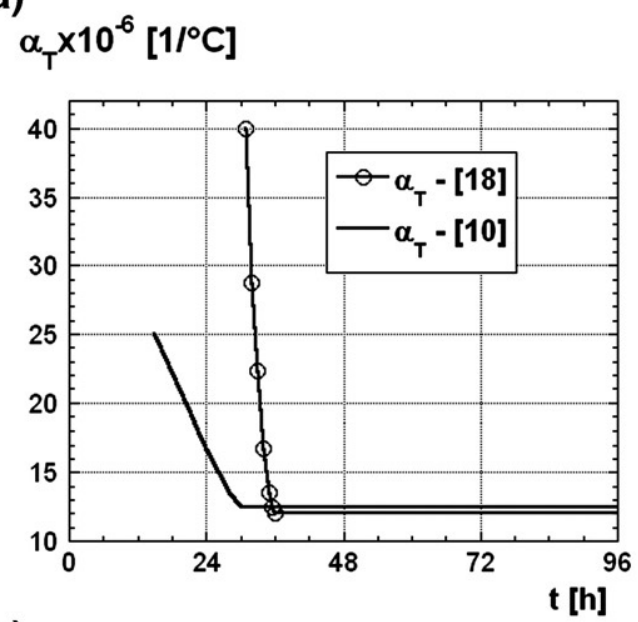

b)

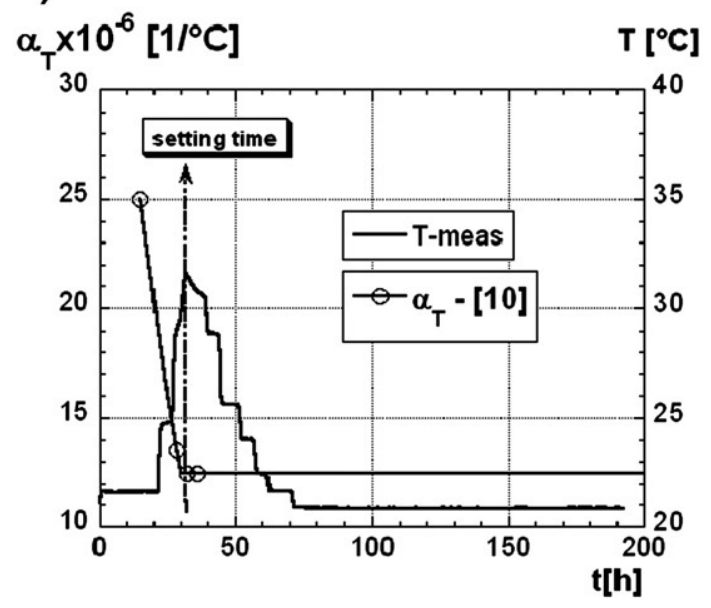

Fig. 12. Comparison of CDT proposed by [18] and adapted by [10] a) and realistic temperature and CDT adapted by [10] b).

$12 \times 10^{-6}\left[{ }^{\circ} \mathrm{C}^{-1}\right]$. We attribute the similarity between these two predictions in the initial phase to the de layed setting observed in the UHPFRC, which begins approximately between 20 and $24 \mathrm{~h}$, and in long-term to the use of very close final values. The choice of weaker (CDT) than that adopted by [18], within the whole setting time a llows to reduce the component of the thermal dilation in the total deformation as shown in Fig. 11.

Finally, we can conclude that this result is correct at least for this material and the studied domain of temperature. These values must be validated by experiments. There is, therefore, more work to be made in this field, because it is necessary to know the DTC evolution of this specific cementitious material, to separate the thermal effect from autogenous shrinkage.

\subsection{Induced stresses prediction for different curing conditions}

The input data for these numerical simulations are obtained from experimental results namely: the thermal properties deduced by applying the Danish model $[10,14,18]$ to semiadiabatic test results [10], the compressive strength, tensile strength, elastic modulus and the autogenous shrinkage. The 


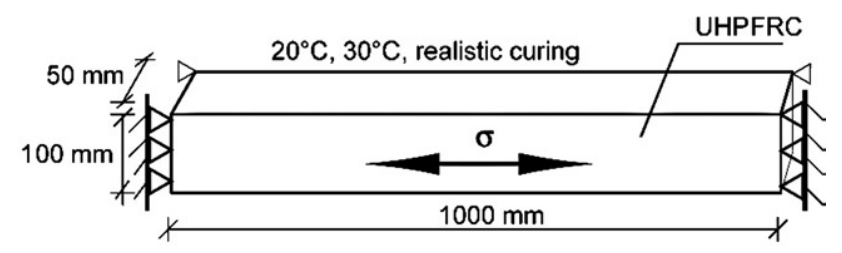

Fig. 13. Dimensions and boundary conditions of UHPFRC specimen for induced stresses simulations.

dimensions and the boundary conditions considered for these simulations are shown in Fig. 13.

Fig. 14a shows the experimental and the predicted induced stresses under a quasi-isothermal temperature of $20{ }^{\circ} \mathrm{C}$. According to this figure, we can observe that the model predicts stresses close to those obtained experimentally in the TSTM, and stays in the range of variability of the measurement, Fig. 3b. This figure shows also the benefit effect of the UHPFRC visco-elastic behavior at early age, which allows mitigation of induced stresses. In fact, the predicted induced stresses considering the material as purely elastic are reduced by about $67 \%$ thanks to the UHPFRC visco-elasticity, due to relaxation [10].

Once, the measurement for $20{ }^{\circ} \mathrm{C}$ validated, a new series of simulations was performed to verify again the validity of MLS to describe the thermo-mechanical effects i.e. the induced stresses at early age under total restrained conditions and various curing, in this case quasi-isothermal temperature of

\section{a)}

\section{Stress [MPa]}

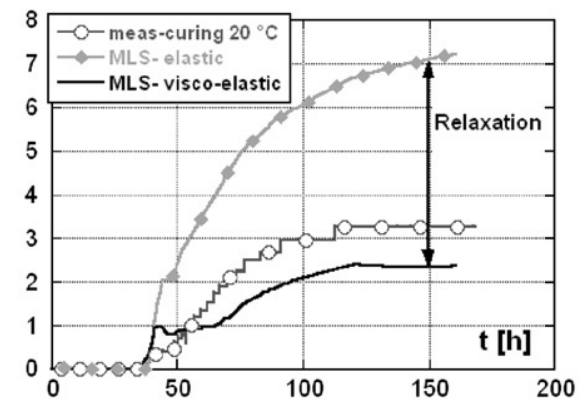

b)

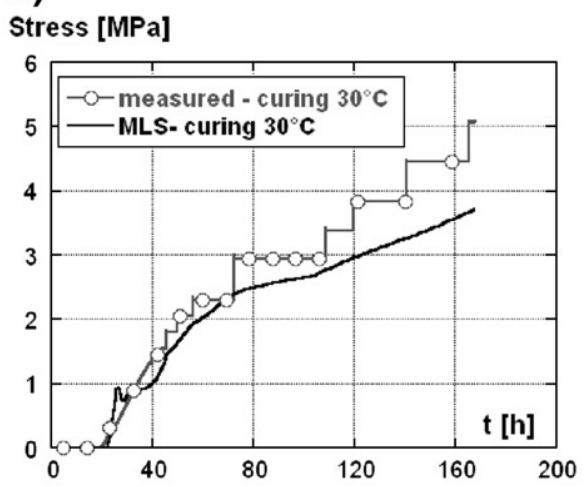

Fig. 14. Induced stresses test and predicted results comparison: for $20{ }^{\circ} \mathrm{C}$ a) and for $30^{\circ} \mathrm{C} \mathrm{b}$ ).

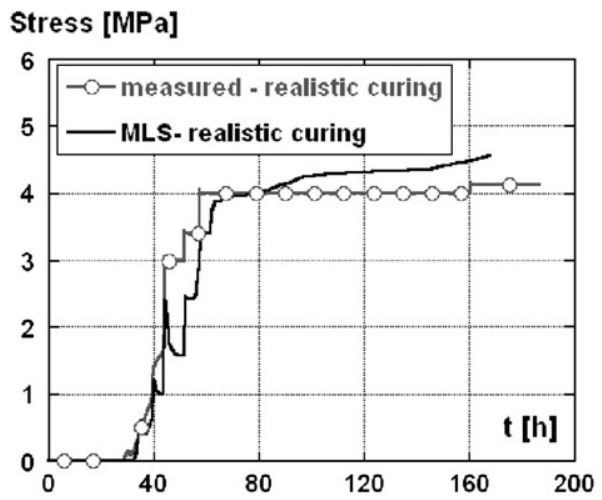

Fig. 15. Induced stresses test and predicted results for realistic temperature evolution.

$30{ }^{\circ} \mathrm{C}$ and realistic temperature. For each simulation, only the curing condition was modified.

Figs. $14 \mathrm{~b}$ and 15 show the prediction obtained for quasiisothermal temperature of $30{ }^{\circ} \mathrm{C}$ and realistic temperature during the 7 days. We can observe that the model describes well the influence of the temperature on the evolution of the stresses. The predicted results approach the measured ones. This is coherent with other validations of the model for stresses developed under incremental full restraint and total restraint [10]. These results confirm again that the influence of the curing conditions on the stresses is monotonous as observed previously by $[1,2]$.

\section{Conclusions}

- Experiments performed on UHPFRC demonstrate that this material exhibits moderate autogenous shrinkage and a low shrinkage induced stress until 7 days. This moderate autogenous shrinkage is attributed to the low evolution of hydration despite the high volume of paste characterizing the UHPFRC mixture.

- The development of stresses under full restraint, at early age, remains moderate with respect to the tensile properties of the UHPFRC tested. According to our opinion, this level of stress seems to be too low to initiate cracks on the UHPFRC, as no cracks were observed after visual inspection of the specimens.

- Increased temperature accelerates the hydration process at early age and consequently all resulting processes that interact at early age are thermo-activated.

- Low temperature causes a reverse effect on UHPFRC autogenous shrinkage, this result confirms findings of previous works reported in the literature for other cementitious materials.

- UHPFRC thermal dilation coefficient should be determined experimentally to confirm the assumed values within this work.

- The traditional maturity concept is not valid to describe the autogenous shrinkage evolution at low temperatures.

- Existing models and implemented in MLS are valid to describe induced stresses at $20{ }^{\circ} \mathrm{C}, 30{ }^{\circ} \mathrm{C}$ and realistic temperature conditions. 


\section{Acknowledgments}

This project was financially supported by the Swiss National Science Foundation and by the Swiss Federal Office for Education and Science in the context of the European project "Sustainable and Advanced Materials for Road Infrastructures" (SAMARIS). The authors thank Roland Gysler for his help in performing the tests.

\section{References}

[1] Ø. Bjontegaard, Thermal dilatation and autogenous deformation as driving forces to self-induced stresses in high performance concrete, $\mathrm{PhD}$ thesis, Trondheim, Norway, 256 pp., 1999.

[2] J.P. Charron, Contribution à l'étude du comportement au jeune âge des matériaux cimentaires en conditions des déformations libre et restreinte, $\mathrm{PhD}$ thesis, Université Laval, Québec, Canada, 332 pp., (in French), 2003.

[3] G. Toma, Comportement des bétons au jeune âge, $\mathrm{PhD}$ thesis, Université Laval, Québec, Canada, 262 pp., (in French), 1999.

[4] H. Hedlund, Hardening concrete-measurements and evaluation of nonelastic deformation and associated restraint stresses, $\mathrm{PhD}$ thesis 2000:25, Lulea University, Sweden, 394 pp., 2000.

[5] M. Behloul, K.C. Lee, Ductal ${ }^{\circledR}$ Seonyu footbridge, Struct. Concr. 4 (2003) 195-201.

[6] O. Bonneau, M. Lachemi, E. Dallaire, J. Dugat, P.C. Aïtcin, Mechanical properties and durability of two industrial reactive powder concretes, ACI Mater. J. 94 (1997) 286-290.

[7] M. Cheyrezy, V. Maret, L. Frouin, Microstructural analysis of RPC (Reactive Powder Concrete), Cem. Concr. Compos. 25 (1995) 1491-1500.

[8] J. Dugat, N. Roux, G. Bernier, Etude expérimentale de la déformation sous contrainte et du comportement à la rupture du béton de poudres réactives (BPR), Annales de L'I.T.B.T.P. 532 (1995) 112-121.

[9] P.C. Aitcin, M. Lachemi, R. Adeline, P. Richard, The Sherbrooke Reactive Powder Concrete Footbridge, Struct. Eng. Int. 2 (1998) 140-144.

[10] A. Kamen, Comportement au jeune âge et différé d'un béton écrouissant sous les effets thermomécaniques, $\mathrm{PhD}$ thesis, No. 3827, Ecole Polytechnique Fédérale de Lausanne, Suisse, 246 pp., (in French), 2007 a.

[11] K. Kovler, Testing system for determining the mechanical behavior of early age concrete under restrained and free uniaxial shrinkage, Rilem Mat. Struct. 27 (1994) 324-330.

[12] K. Kovler, S.I. Igarashi, A. Bentur, Tensile creep behavior of high strength concretes at early ages, Rilem Mat. Struct. 32 (1999) 383-387.

[13] Femmasse, Software (MLS: Multi-layer system), Developed by Femmasse, $2007 \mathrm{http}: / /$ www.femmasse.nl.

[14] Bernard, Comportement à long terme des éléments de structure formés de bétons d'âges différents, $\mathrm{PhD}$ thesis No. 2283, Ecole Polytechnique Fédérale de Lausanne, Suisse, 238 pp., (in French), 2000.

[15] P.E. Roelfstra, A numerical approach to investigate the properties of concrete - numerical concrete, $\mathrm{PhD}$ thesis No. 788, Ecole Polytechnique Fédérale de Lausanne, Suisse, 199 pp., 1989.

[16] P. Rossi, A. Arca, E. Parant, P. Fakhri, Bending and compressive behaviors of a new cement composite, Cem. Concr. Res. 33 (2005) 27-33.

[17] J.P. Charron, E. Denarié, E. Brühwiler, Permeability of UHPFRC under high stresses, RILEM Symposium, Advances in Concrete Through Science and Engineering, March 22-24, Evanston, USA, 2004, CD-ROM, 12 pp.

[18] K. Habel, Structural Behavior of Elements Combining Ultra-High Performance Fibre Reinforced Concretes (UHPFRC) and Reinforced Concrete, PhD thesis No. 3036, Ecole Polytechnique Fédérale de Lausanne, Suisse, (http://ahdoc.epfl.ch/EPFL/theses/ 2004/3036/EPFL_TH3036.pdf), 195 pp., 2004.

[19] E. Denarié, Structural rehabilitations with Ultra-High Performance Fibre Reinforced Concretes (UHPFRC), in: M. Alexander, H.D. Beushausen, F. Dehn, P. Moyo, Taylor, Francis (Eds.), Keynote Lecture, ICCRRR International Conference on Concrete Repair, Rehabilitation and Retrofitting, 21-23 November, Cape Town, South Africa, 2005, book with extended summaries and CD-ROM with full papers.
[20] A. Kamen, E. Denarié, E. Brühwiler, Mechanical behavior of Ultra High Performance Fibre Reinforced Concretes (UHPFRC) at early age, and under restraint, in: G. Pijaudier-Cabot, B. Gérard, P. Acker, Hermès Publishing (Eds.), Proc. CONCREEP vol. 7 (2005) 591-596.

[21] M. Sule, K. Van Breugel, Cracking behavior of reinforced concrete subjected to early-age shrinkage, in: V. Baroghel Bouny, P.C. Aitcin (Eds.), Proc. of the International RILEM Workshop, 2000, pp. 417-433.

[22] L. Barcelo, S. Boivin, P. Acker, J. Toupin, B. Clavaud, Early age shrinkage of concrete: back to physical phenomena, Concr. Sci. Eng., RILEM 3 (10) (2001) 85-91.

[23] A. Kamen, E. Denarié, E. Brühwiler, Thermal effects on physicomechanical properties of UHPFRC, ACI Mater. J. N¹04-M47 (2007) 415-423.

[24] Ø. Bjontegaard, T.A. Hammer, E.J. Sellevold, On the measurement of free deformation of early age cement paste and concrete, Cem. Concr. Compos. 26 (2004) 427-435.

[25] A. Kamen, E. Denarié, E. Brühwiler, Proc of Developments in Structural Engineering, Mechanics and Computation 3, of the Third International Conference on Structural Engineering, 10-12 September 2007, Department of Civil Engineering, University of Cape Town, Rondebosch 7701, Cape Town, South Africa, Edited by Alphose. Zingoni, Millpress Science RotterdamNetherlands Publishing, book with extended summaries pp. 533-534 and CD-ROM with full papers, 2007.

[26] A. Kamen, Time dependent behavior of ultra high performance fibre reinforced concrete, 6th International PhD Symposium in Civil Engineering, Zurich, 2006, book with extended summaries and CD-ROM with full papers.

[27] A.M. Neville, Properties of Concrete, Forth and final editionAddison Wesley Longman Limited0-582-23070-5, 1995.

[28] A. Radocea, Autogenous volume change of concrete at very early age, Mag. Concr. Res. 50 (1998) 107-113.

[29] A.M. Neville, J. Brooks, Concrete Technology, Longman Scientific and Technical, 1987438 pp.

[30] W.H. Bray, E.J. Sellevold, Water sorption properties of hardened cement paste cured or stored at elevated temperature, Cem. Concr. Res. 3 (1973) $723-728$.

[31] I. Odler, J. Skalny, Hydration of tricalcium silicate at elevated temperature, J. Appl. Chem. Biotechnol. 23 (1973) 661-667.

[32] O.M. Jensen, P.F. Hansen, Influence of temperature on autogenous deformation and relative humidity change in hardening cement paste, Cem. Concr. Res. 29 (1999) 567-575.

[33] P.F. Hansen, E.J. Pedersen, Maturity computer for controlled curing and hardening of concrete, Nord. Betong 1 (1977) 21-25.

[34] Rilem TC 119-TCE, Avoidance of thermal cracking in concrete at early ages, RILEM Mat. Struct. 30 (1997) 451-464.

[35] U. Korhonen, E. Vilhonen, On the calculation of activation energy in thermal activation rate processes, Acta Polytech. Scand. 22 (1963).

[36] H. Kada, M. Lachmi, N. Petrov, O. Bonneau, P.-C. Aïtcin, Determination of the coefficient of thermal expansion of high performance concrete from initial setting, Mat. Struct. 35 (2002) 35-41.

[37] P. Laplante, C. Boulay, Evolution du coefficient de dilatation thermique du béton en fonction de sa maturité aux tout premiers âges, Mat. Struct. 27 (1997) 596-605.

[38] A.A. Khan, W.D. Cook, D. Mitchell, Thermal properties and transient thermal analysis of structural members during hydration, ACI Mater. J. 95 (1998) 293-303.

[39] Z.C. Grasley, D.A. Lange, Thermal dilation and internal relative humidity of hardened cement paste, Mat. Struct. 40 (2007) 311-317.

[40] E.J. Sellevold, O. Bjontegaard, Coefficient of thermal expansion of cement paste and concrete: mechanisms of moisture interaction, Mat. Struct. 39 (2006) 809-815.

[41] AFGC, Association Française du Génie Civil, Bétons fibrés à ultra hautes performances (ultra high performance fibre-reinforced concretes), SETRA-Service d'études techniques des routes et autoroutes, France, 2002, p. 152. 